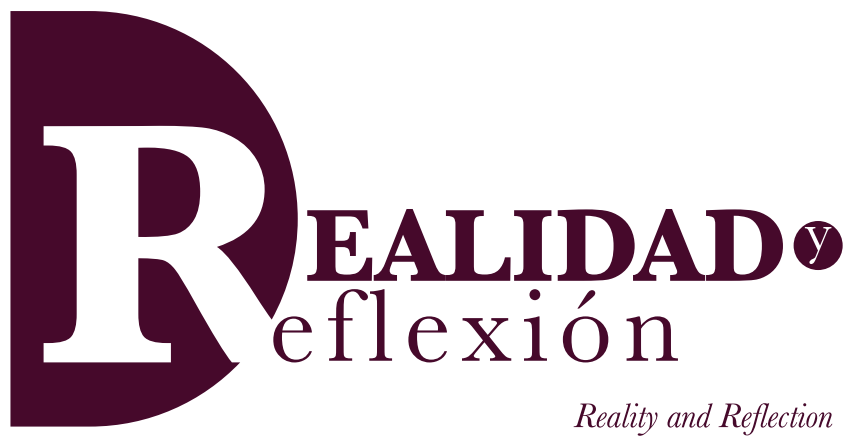

ISSN 1992-6510

Año 20, N 52, San Salvador, El Salvador, Centroamérica. Revista Semestral Julio-Diciembre 2020

YEAR 20, N52, SAN SALVADOR, EL SALVADOR, CENTRAL AMERICA. SEMESTRAL JOURNAL JULY-DECEMBER 2020

\title{
Diagnóstico situacional de la niñez y adolescencia indígena en E1 Salvador
}

\author{
Situational diagnosis of indigenous childhood and \\ adolescence in El Salvador
}

Mdh. Víctor Manuel Miranda Guzmán Docente universitario, Maestro en Derechos Humanos y Educación para la Paz, Licenciado en Ciencias Jurídicas; y postgrado en Pedagogía todos por la Universidad de El Salvador licenciadovictormiranda@hotmail.com

Claudia Rebeca Centeno Argueta Estudiante de la Licenciatura en Relaciones Internacionales de la Universidad Francisco Gavidia centeno.claudiar@gmail.com

Alba Marianela Santana Valencia Estudiante de la Licenciatura en Relaciones Internacionales de la Universidad Francisco Gavidia albamar.sanva@gmail.com

Recibido: 29 de mayo de 2020 Aprobado: 22 de julio de 2020 DOI: $10.5377 /$ ryr.v52is2.10640 


\section{RESUMEN}

El propósito del artículo es propiciar e identificar las condiciones materiales y espirituales de vida de la niñez y adolescencia de los pueblos Náhuat, Lenca y Kakawira; a través de sus experiencias comunitarias observadas desde las principales áreas de la realidad de los Pueblos Indígenas, empleando la metodología cualitativa fenomenológica, por medio de una revisión bibliográfica y un análisis de contendido etnológico, histórico, normativo, de políticas públicas; así como de descripción y comprensión de los fenómenos desde la cosmovisión, principios, valores y discursos de los Pueblos Indígenas.

Los resultados establecieron que en el devenir histórico los Pueblos Indígenas sufrieron sistemática y continuamente vulneración de sus derechos fundamentales y humanos, lo que produjo la abolición de su cultura, cosmovisión, religión, negación de sus instituciones, sistema de salud, sistema económico, forma de organización, vestuario, lengua y el despojo violento de sus tierras; además de históricamente negárseles su condición como sujeto de derecho, hasta su reconocimiento constitucional con la reforma del artículo sesenta y tres.

El proceso de alienación occidental en que se encuentran inmersos los niños y adolescentes indígenas, pone en peligro el traspaso generacional de su cosmovisión, en razón de la pérdida de identidad y pertenencia; así mismo la LEPINA empodera al niño y al adolescente de sus derechos, sin correspondencia de sus obligaciones como integrante de la comunidad, vulnerando los principios, valores y cosmovisión del proceso de enseñanza aprendizaje indígena; en razón de no propiciar el derecho llave de la consulta de consentimiento libre, previo e informado en la formulación de las leyes y políticas públicas.

Palabras claves: Pueblos Indígenas, Náhuat, Lenca, Kakawira, Derechos Humanos, niñez, adolescencia, cosmovisión.

\section{ABSTRACT}

The purpose of the article is to promote the identification of material and spiritual conditions of life of the childhood and adolescence of the Náhuat, Lenca and Kakawira peoples; through their community experiences observed from the main areas of the reality of Indigenous Peoples, using the phenomenological qualitative methodology, through a bibliographic review and an analysis of content ethnological, historical, normative, public policy; as well as a description and understanding of phenomena from the worldview, principles, values and discourses of Indigenous Peoples.

The results established that, in the historical evolution, Indigenous Peoples suffered systematically and continuously violation of their fundamental and human rights, which led to the abolition of their culture, worldview, religion, denial of their institutions, health system, economic system, form of organization, 
clothing, language and the violent dispossession of their lands; in addition to being historically denied their status as a subject of law, until their constitutional recognition with the reform of article sixty three.

The process of western alienation in which indigenous children and adolescents are immersed, jeopardizes the generational transfer of their worldview, due to the loss of identity and belonging; likewise, LEPINA empowers children and adolescents of their rights, without matching their obligations as a member of the community, violating the principles, values and worldview of the indigenous learning-teaching process; in reason of not promoting the key right of free, prior and informed consultation in the formulation of laws and public policies.

Keywords: Indigenous Peoples, Náhuat, Lenca, Kakawira, Human Rights, childhood, adolescence, worldview. 


\section{Introducción}

Este artículo busca identificar las condiciones de vida de la niñez y adolescencia de los Pueblos Náhuat, Lenca y Kakawira; a través de sus experiencias comunitarias observadas desde las principales áreas de la realidad de los Pueblos Indígenas, y contextualizadas en términos de temporalidad, espacio y contexto, empleando la metodología cualitativa fenomenológica, por medio de una revisión bibliográfica y un análisis crítico y exhaustivo de contenido etnológico, histórico, normativo, de políticas públicas y corrientes que las sustentan; así como de sus paradigmas; y la descripción y comprensión de los fenómenos desde la óptica de la cosmovisión, principios, valores y discursos de los Pueblos Indígenas.

Los resultados de la investigación establecieron que en el devenir histórico los Pueblos Indígenas sufrieron sistemática y continuamente de invisibilización, negación y vulneración de sus derechos fundamentales $\mathrm{y}$ humanos, lo que produjo la abolición de su cultura, cosmovisión, religión, negación de sus instituciones, sistema de salud, sistema económico, forma de organización, vestuario, lengua y el despojo violento de sus tierras; además de históricamente negárseles su condición como sujeto de derecho, hasta su reivindicación por medio del reconocimiento constitucional de la reforma del artículo sesenta y tres. Aunado a lo anterior, en materia de legislación secundaria, las regulaciones históricamente fueron lesivas y vulneradoras de sus derechos y carentes de un desarrollo sustantivo en materia de derecho indígena.

Otro de los hallazgos de la investigación radica en el proceso de alienación de la identidad del indígena salvadoreño, lo cual ha llevado a condiciones materiales y espirituales de pérdida de identidad y pertenencia de las nuevas generaciones; sin embargo, existe un reconocimiento de colectividad en su cotidianidad, lo que difiere con la fragmentación occidental de la sociedad en grupos (persona mayores, adolescentes, mujeres y otros), permitiendo la interacción de todos los integrantes de la comunidad en las diversas actividades que realizan, un ejercicio individual de determinación de su propia identidad cultural reconociéndose en aquella del grupo.

Por otra parte, existe un reconocimiento pleno de las obligaciones del Estado de respetar, proteger y satisfacer los derechos del niño y adolescente, en razón que la tutela efectiva de los mismos, se convierte en la piedra angular sobre la que se erige todo el andamiaje de garantías fundamentales. Los informantes claves reconocen la Ley de Protección Integral de la niñez y adolescencia y la política de niñez y adolescencia y manifiestan que no existe una disputa con ella, pero señalan debilidades, como el empoderamiento del niño y del adolescente de sus derechos, sin correspondencia a sus obligaciones como integrante de la colectividad en su contexto material y espiritual y la vulneración del derecho a una consulta de consentimiento libre, previo e informado en la formulación del marco normativo y las políticas de Estado.

\section{Justificación}

Hablar de niñez y adolescencia indígena en E1 Salvador es hablar de procesos de represión e invisibilización de los Pueblos Náhuat, Lenca y Kakawira. Los Acuerdos de Paz en 1992, 
abrieron las puertas para que los Pueblos Indígenas se reagruparan en diferentes estructuras organizativas comunitarias y nacionales, como el Consejo Coordinador Nacional Indígena Salvadoreño "CCNIS", fortaleciendo así la identidad cultural y reivindicando los derechos de los Pueblos Indígenas. En la actualidad, no se cuenta con información detallada y datos desagregados en el desarrollo de los esfuerzos censales y de encuestas recientes. A pesar de esta deuda histórica por parte del Estado salvadoreño, existen tres fuentes sobre población indígena en el país: la Encuesta de Hogares de Propósitos Múltiples del año 2005, el Perfil de los Pueblos Indígenas en El Salvador y el VI Censo de población y V de Vivienda del año 2007. Cada una de estas fuentes muestra discrepancias considerables en cuanto a la población indígena que se identifica en el país (ver tabla 1 para conocer las discrepancias porcentuales). al equipo multidisciplinario que elaboró el cuestionario del censo, donde participaron: representantes residentes del Programa de las Naciones Unidas para el Desarrollo (PNUD) y del Fondo de Población de las Naciones Unidas (UNFPA), la directora para E1 Salvador de la Agencia de los Estados Unidos para el Desarrollo Internacional (USAID), la representante del Banco Interamericano de Desarrollo (BID), Comisión Nacional de Desarrollo (CND), Asociación de Radio y Programas Participativos de El Salvador (ARPAS), Asociación Nacional de la Empresa Privada (ANEP), Corporación de Municipalidades de la República de E1 Salvador (COMURES), el Centro Latinoamericano y Caribeño de Demografía (CELADE), Centro Nacional de Registros (CNR), Fuerza Armada de El Salvador, Policía Nacional Civil (PNC) organizaciones indígenas y Pueblos Indígenas (DIGESTYC, 2007). Dicho grupo validó la

\section{Tabla 1}

Datos de población en porcentaje de Pueblos Indígenas según diversas fuentes

\begin{tabular}{l|c|c}
\hline Documento & Año & Porcentaje \\
\hline Perfil de los Pueblos Indígenas en El Salvador & 2003 & $10-12$ \\
\hline Encuesta de Hogares de Propósitos Múltiples & 2005 & 17 \\
\hline Censo de Población y Vivienda & 2007 & 0.23 \\
\hline
\end{tabular}

Fuente: Elaboración propia a partir de los datos generados por el Perfil de Pueblos Indígenas en E1 Salvador, la Encuesta de Hogares de Propósitos Múltiples y el Censo de Población y Vivienda realizado en el año 2007.

Durante el levantamiento de los Censos Nacionales VI de Población y V de Vivienda 2007, realizados durante el periodo del 12 al 27 de mayo de 2007, funcionarios de la DYGESTIC modificaron sin consulta previa siguiente pregunta a realizarse en el censo: Según sus antepasados y prácticas culturales ¿se considera usted miembro de un pueblo indígena? Si es así, diga ¿cuál? (Comisión Internacional de Juristas, 2013, p. 87). 
La pregunta fue sustituida por otra que pedía a las personas adscribirse a una "raza", la cual fue redactada de la siguiente forma (DIGESTYC, 2008, p. 4):

\begin{tabular}{l|l}
\hline \multicolumn{2}{l|}{$\mathbf{\text { A ¿ } E s ~ u s t e d ? ~}$} \\
\hline Blanco & \\
\hline Mestizo & (mezcla de blanco con indígena). \\
\hline Indígena & pase a pregunta 6 B. \\
\hline Negro & (de raza). \\
\hline Otro. & \\
\hline 6 B. Si usted es indígena ¿A cuál grupo pertenece? \\
\hline Lenca & 6 \\
\hline $\begin{array}{l}\text { Kakawira } \\
\text { (Cacaopera) }\end{array}$ & 7 \\
\hline Nahua pipil & 8 \\
\hline Otro especifique & 9 \\
\hline
\end{tabular}

Cabe acotar que los empadronadores, atendiendo criterios propios, decidían realizar o no las preguntas 6 A y $6 \mathrm{~B}$, puntualiza Jesús Amadeo Martínez (2019), Consejero Mayor del Consejo Indígena de Centro América CICA; lo que originó como resultado, que menos del $1 \%$ de la población total de El Salvador; es decir, trece mil indígenas se autodenominaran pertenecientes al grupo poblacional referido, lo que resultó cuestionado fuertemente por el Comité para la Eliminación de la Discriminación Racial (Comisión Internacional de Juristas, 2013). Otro de los señalamientos realizados fue que los indígenas no fueron capacitados por la DIGESTYC para participar como empadronadores, lo cual hubiese dado confianza a los censados, en razón que debido a la represión histórica que este núcleo poblacional ha tenido a lo largo de la historia, se carece de confianza para facilitar este tipo de información (Martínez, 2019).
En razón de la experiencia referida, en abril de 2018, se inició un proceso de levantamiento de datos para realizar un censo municipal en el municipio de Cacaopera, con la coordinación de DIGESTYC, FAO, UNICEF, CCNIS $\mathrm{y}$ las organizaciones indígenas territoriales, para tener datos desagregados, que incluyeran un apartado sobre Pueblos Indígenas, donde de forma extraoficial se conoció que, en los datos obtenidos, más del $80 \%$ se consideraron Indígenas (FAO, 2018).

\section{Marco de referencia}

Este apartado desarrolla, en primer lugar, la descripción etnológica indígena salvadoreña, su relevancia radica en identificar la procedencia, territorialidad y características que identifican al indígena salvadoreño; es decir, la particularización sobre qué es ser indígena en E1 Salvador, sustentado con ello el sujeto de investigación; posteriormente, se desarrollan los antecedentes históricos, un elemento neurálgico para fundamentar, comprender y analizar críticamente la condición material y espiritual del indígena en El Salvador; sin el antecedente histórico sería incomprensible la condición del sujeto de estudio, en razón que extraeríamos al indígena de la realidad en la que se ha encontrado inmerso en el devenir histórico y por lo tanto estaríamos ante un sujeto carente de historia.

El marco normativo (Constitución, leyes secundarias, ordenanzas municipales entre otros) es un elemento fundamental para comprender la condición y situación jurídica del indígena, en razón que históricamente fue reprimido e invisibilizado por la superestructura jurídica lesiva y vulneradora de sus derechos fundamentales 
y humanos, debido a que desarraigaron a la población de sus tierras, a través de las instituciones de la expropiación y extinción; desarticularon la organización social indígena, destruyeron y desconocieron sus instituciones, $y$ prohibieron su cosmovisión, lengua y vestuario, legalizando y legitimando la actuación de los obtentores del poder en el devenir histórico. Lo anterior explica las condiciones materiales en las que se encuentran en la actualidad y la lucha por las reivindicaciones y el reconocimiento como sujeto de derecho.

A continuación, se desarrollan las políticas referentes a los Pueblos Indígenas en general y a la niñez y juventud en particular, con la finalidad de comprender la concepción del Estado a partir de la concreción de ideales, que se construyen de dinámicas sociales que requieren ser interpretadas y llevadas a una toma de decisiones capaces de ser administradas y continuamente revisadas, lo que constituye el ser y sentir del administrador público. Por último, se presentan las corrientes doctrinarias que fundamentan las políticas sobre la niñez y adolescencia en El Salvador, las cuales sustentan científicamente los términos, conceptos, objetivos, finalidad, filosofía, instituciones, estrategias, líneas de acción, mecanismos de implementación, monitoreo y evaluación con el que se implementa la concepción del Estado con relación a la niñez $\mathrm{y}$ adolescencia salvadoreña.

\section{Descripción etnológica indígena salvadoreña}

Los Pueblos Indígenas del país corresponden al área geográfica cultural de Mesoamérica Náhuat, con influencias del tronco Chibcha del Norte de América del Sur. Su presencia data del período
Arcaico (8000 a. C. - 2000 a. C.), durante el cual se colonizó la planicie costera, ocupada hoy por E1 Salvador, según explica Jesús Amadeo Martínez, Consejero Mayor del Consejo Indígena de Centro América CICA (Martínez, 2019). E1 territorio salvadoreño es habitado actualmente por tres Pueblos Indígenas: los Náhuat / Pipiles, los Lencas, y los Kakawira.

E1Pueblo Náhuat Pipil habita en el departamento de Ahuachapán, en los municipios de Concepción de Ataco, San Francisco Menéndez, San Pedro Puxtla, Tacuba y Apaneca, en el departamento Santa Ana, en los municipios de Texistepeque y Chalchuapa, en el departamento de Sonsonate, en los municipios de Caluco, Cuisnáhuat, Izalco, Juayúa, Nahuizalco, Salcoatitlán, San Antonio del Monte, San Julián, Santa Catarina Mazahuat, Santa Isabel Ishuatán, Santo Domingo de Guzmán y Sonzacate con la característica de encontrase dispersos en barrios urbanos y sector rural.

En la zona central del país, en el departamento de La Libertad, en los municipios Jicalapa, Chiltiupán, Huizúcar, Jayaque, Teotepeque, Tepecoyo y Talnique; en el departamento de San Salvador, en los municipios de Panchimalco, Rosario de Mora, Santiago Texacuangos, San Antonio Abad y Tonacatepeque; en el departamento de Cuscatlán, en los municipios de Cojutepeque, San Pedro Perulapán, Santa Cruz Analquito, Monte San Juan, Tenancingo y Santa Cruz Michapa; en el departamento de La Paz, en los municipios de San Antonio Mazahuat, San Pedro Masahuat, San Francisco Chinameca, San Juan Nonualco, Zacatecoluca, San Pedro Nonualco, Santiago Nonualco, San Juan Tepezontes, San Miguel Tepezontes y en 
cantones de Santa María Ostuma (Ministerio de Cultura et al., 2017).

Con respecto al departamento de San Vicente, en los municipios de Apastepeque y San Sebastián, y por último en el departamento de Chalatenango, en los municipios de Tejutla y Nueva Concepción, la lengua que aún se habla es el náhuat (Martínez, 2019).

El pueblo Lenca se localiza en el departamento de Usulután, la concurrencia se da en Jiquilisco en los cantones Salinas, E1 Potreo y Puerto Los Ávalos, y en los municipios de Ereguayquín, Ozatlán y Tecapán; en el departamento de San Miguel, en los municipios de Lolotique y Moncagua; en el departamento de Morazán en los municipios de Chilanga, Guatajiagua, San Simón y Sensembra y en el departamento de La Unión, en los municipios de Conchagua y Yucuaiquín. Su idioma es el potón (Martínez, 2019).

El pueblo kakawira, habita en el departamento de Morazán, en el municipio de cacaopera (Ministerio de Cultura et al., 2017), la lengua que aún se habla es el cacaopera o kakawira según explica Jesús Amadeo Martínez, Consejero Mayor del Consejo Indígena de Centro América CICA (Martínez, 2019).

Con respecto a la población indígena en $\mathrm{El}$ Salvador, el censo de 1930 identificó un total de 79,573 indígenas lo cual se traduce a un 5.6\% de la población. En la década de los noventa se estimaba que la población indígena fluctuaba entre un $7 \%$ y un $10 \%$ de la población total de 539,000 personas. Posteriormente, a inicios de la década del dos mil, los indígenas indicaron ser entre un 10 y un $12 \%$ de la población nacional.
En el año 2007, con base en el IV Censo de Población y el $\mathrm{V}$ de Vivienda, la población indígena de E1 Salvador se estimó en un 0.23\% de la población nacional, lo cual equivale a 13,310 personas (ver tabla 2) que, según el censo, se identificaron como indígena (Ministerio de Cultura et al., 2017).

\section{Tabla 2}

Población indigena por departamento de acuerdo al Censo de Población y Vivienda del 2007

\begin{tabular}{c|c}
\hline Departamento & Población \\
\hline Ahuachapán & 199 \\
\hline Santa Ana & 251 \\
\hline Sonsonate & 1,944 \\
\hline Chalatenango & 34 \\
\hline La Libertad & 689 \\
\hline San Salvador & 3198 \\
\hline Cuscatlán & 54 \\
\hline La Paz & 93 \\
\hline Cabañas & 46 \\
\hline San Vicente & 290 \\
\hline Usulután & 157 \\
\hline San Miguel & 902 \\
\hline Morazán & 4723 \\
\hline La Unión & 730 \\
\hline Total & $\mathbf{1 3 , 3 1 0}$ \\
\hline
\end{tabular}

Fuente: Tomada de Donis Jorge, Subsecretaría de Desarrollo Territorial y Descentralización, Secretaría de Asuntos Estratégicos de la Presidencia "Marco para los Pueblos Indígenas", Proyecto de fortalecimiento de gobiernos locales, San Salvador, 7 de abril 2010, página 4.

Los pueblos indígenas en El Salvador se caracterizan por su conciencia de pertenecer o descender de un pueblo indígena, sus prácticas espirituales, su tejido organizativo, su auto determinación de ser indígena, la conservación de sus conocimientos y saberes, rasgos físicos, su 
especial relación con la madre tierra y los recursos naturales y en algunas ocasiones por su lengua y su vestuario, manifiesta Martínez (2019).

\subsection{Antecedentes históricos}

Los pueblos indígenas que habitan las tierras de Cuscatlán nombraron a su territorio como Cushcatan que significa "Lugar de Piedras Preciosas" (CONCULTURA, 2000). Sin embargo, han sufrido históricamente el aniquilamiento sistemático de su identidad y cultura ancestral desde la época de la invasión colonialista del imperio español, a través del sometimiento de la cruz y la espada, bajo el argumento de la instauración de un proceso civilizatorio a lo que para ellos eran razas inferiores e incultas regidas por mitos y leyendas (Dalton, 2006).

Ello condenó a los antepasados a venerar al Dios de los conquistadores, la abolición de su religión, la negación de sus instituciones y su lengua materna (Anderson, 2001), constructo caracterológico de la identidad de los pueblos indígenas; quienes, aunado a lo anterior se vieron forzados al despojo violento de sus tierras; a través de la creación de marcos normativos e instituciones que legalizaron y legitimaron la concentración de la tenencia de la tierra en una clase social dominante durante la época colonial (Dalton, 2006).

Lo anterior, se acentuó a raíz de diversas acciones políticas a través de las cuales se sometió a nuestros ancestros al régimen instituido; pues el no hacerlo habría producido su aniquilación total. Esta situación persistió después de la independencia de las Provincias Unidas de Centroamérica (Anderson, 2001).
Debemos acotar que las diversas sublevaciones a lo largo de este periodo histórico como el caso de la suscitada por los Nonualcos en 1833 (Domínguez, 2007), y el levantamiento indígena campesino de 1932 (Gould y Lauria-Santiago, 2010), tuvieron su asidero en reivindicaciones históricas, políticas, socioeconómicas y jurídicas, debido a las precariedades de subsistencia que aquejaban a los pueblos indígenas, tras la expropiación por parte del Estado Salvadoreño de las tierras ejidales y comunales (Alvarenga, 2006), en razón de la transformación de la estructura política, socioeconómica y jurídica a partir de principios de la década de los 80 del siglo XIX (Menjivar, 1980).

La respuesta del Estado Salvadoreño ante las exigencias de los pueblos indígenas durante todo ese período histórico, fue la creación de una superestructura política y jurídica que legalizó y legitimó la represión estatal, la cual incluía la negación de su cosmovisión y cultura, forzando a los mismos a vivir en condiciones paupérrimas y marginales, realizando incluso la eliminación física del indígena y consecuentemente con sus descendientes.

Las organizaciones indígenas comenzaron a reagruparse después de los acuerdos de paz en 1992 (Martínez 2019), ofreciendo esta coyuntura histórica, la apertura para poder fortalecer y consolidar el tejido organizativo indígena que había sido invisibilizado violentamente por medio de una persecución histórica, sistemática y continuada, durante la época colonial y posterior a la constitución del Estado Salvadoreño. La lucha reivindicativa de sus derechos posterior a los acuerdos de paz se materializó con la reforma del artículo sesenta y tres de la Constitución, el cual lo reconoció como sujeto de derecho. 


\section{Marco normativo}

\section{Constitución de la República}

Fue hasta el periodo presidencial de 2009 al 2014 que el Estado salvadoreño reconoció la condición de sujeto de derecho de los pueblos indígenas en El Salvador, al reformarse el artículo sesenta y tres de la Constitución, publicado en el Diario Oficial Tomo 385, No. 84 de fecha 9 de mayo de 2012, y su posterior ratificación el día 12 de junio de 2014, estableciéndose de la siguiente forma (Diario Oficial, 2012b):

El Salvador reconoce a los pueblos indígenas y adoptará políticas a fin de mantener y desarrollar su identidad étnica y cultural, cosmovisión, valores y espiritualidad (...) como una deuda histórica del Estado Salvadoreño de dotarlos de una protección especial para garantizar sus derechos, especialmente los que ejercen de manera colectiva, conforme a su cosmovisión indígena, formas de vida y tradiciones.

\section{Legislación secundariay ordenanzas municipales}

En materia de legislación secundaria, los cuerpos normativos fueron lesivos y vulneradores de los derechos fundamentales y humanos de los pueblos indígenas; en razón que desarraigaron a la población de sus tierras, a través de las instituciones de la expropiación y extinción de ejidos, desarticularon la organización social indígena, destruyeron y desconocieron sus instituciones y prohibieron su cosmovisión, lengua y vestuario. Entre las leyes que provocaron las vulneraciones referidas se pueden destacar algunas particularmente.

Se destaca el Código Civil publicado en la Gaceta Oficial $N^{\circ} 85$, Tomo 8 de fecha 14 de abril de1860, aún vigente, que en su libro segundo titulado de los "bienes de su dominio, posesión, uso y goce”, funda a través de los artículos 571 y siguientes, todo el andamiaje superestructural jurídico y político para la expropiación de las tierras que aún quedaban en manos de los pueblos indígenas, a través del reconocimiento de la propiedad privada, la ley de extinción de tierras ejidales y su reglamento de febrero de 1881, la Ley de Extinción de Terrenos Ejidales 1882, la Ley de Vagancia 1882, el decreto legislativo del 6 de abril 1889, la Ley de Extinción de Comunidades de 10 de abril de 1891 y su reglamento de fecha 21 de julio 1891 y la ley del 27 de marzo de 1897 referente a tierras comunales y ejidales que pertenecen a la nación.

\section{Ordenanzas municipales}

En materia de ordenanzas municipales hasta la fecha de publicación del presente artículo, se han publicado seis ordenanzas municipales en materia de tutela de pueblos indígenas de las cuales podemos acotar:

1. La emitida por el Consejo Municipal de Nahuizalco, jurisdicción del departamento de Sonsonate, quien acordó la Ordenanza Municipal denominada "Sobre Derechos de las Comunidades Indígenas asentadas en el Municipio de Nahuizalco" publicada en el Diario Oficial, Tomo No. 392, No. 126 de fecha 8 de julio de 2011, la cual tiene por objeto "promover el desarrollo integral en lo económico, social, cultural y la participación efectiva en el ejercicio de los derechos civiles y políticos, así como de los derechos económicos, sociales y culturales de las comunidades indígenas del municipio" (Diario Oficial, 2011). 
2. La emitida por el Concejo Municipal de Izalco, jurisdicción del Departamento de Sonsonate, quien acordó la Ordenanza Municipal denominada "Sobre derechos de la comunidad indígena de Izalco", publicada en el Diario Oficial Tomo $\mathrm{N}^{\circ} 395, \mathrm{~N}^{\circ} 75$ de fecha 25 de abril de 2012, que tiene por objeto "promover el desarrollo integral y el ejercicio pleno de los derechos civiles y políticos de la comunidad indígena del municipio de Izalco, la cual incluye la protección, conservación y preservación de su propia cultura, tierra, territorio y organización, especialmente de los recursos naturales que constituyen el entorno ecológico de dichas comunidades" (Diario Oficial, 2012a).

3. La emitida por el Concejo Municipal de Panchimalco, jurisdicción del Departamento de San Salvador, quien acordó la Ordenanza Municipal denominada "Ordenanza Municipal sobre derechos de la comunidad indígena de Panchimalco" publicada en el Diario Oficial Tomo $\mathrm{N}^{\circ} 407, \mathrm{~N}^{\circ} 61$, de fecha 8 de abril de 2015, que reconoce la Declaración de las Naciones Unidas sobre derechos de los pueblos indígenas, la Convención internacional sobre la eliminación de todas las formas de discriminación racial y las recomendaciones, interpretaciones y doctrina de los sistemas de Derechos Humanos universal y regional (Diario Oficial, 2015a).

4. La emitida por el Concejo Municipal de Cuisnáhuat, jurisdicción del Departamento de Sonsonate, quien acordó la ordenanza municipal denominada "Sobre derechos de la comunidad indígena de Cuisnáhuat", publicada en el Diario Oficial, Tomo $\mathrm{N}^{\circ} 407$,
$\mathrm{N}^{\circ}$ 80, de fecha 6 de mayo de 2015, la cual tiene como objetivo "promover el desarrollo integral y el ejercicio de los derechos civiles y políticos de la comunidad indígena en la jurisdicción del municipio referido, así mismo reconoce en su artículo cuatro la Declaración de las Naciones Unidas sobre derechos de los pueblos indígenas y en su artículo cinco la Convención internacional sobre la eliminación de todas las formas de discriminación racial" (Diario Oficial, 2015b).

5. La emitida por el Concejo Municipal de Santo Domingo de Guzmán, jurisdicción del Departamento de Sonsonate, quien acordó la Ordenanza Municipal denominada "Ordenanza municipal sobre derechos de las comunidad indígena de Santo Domingo de Guzmán", publicada en el Diario Oficial Tomo $\mathrm{N}^{\circ} 415, \mathrm{~N}^{\circ} 108$ de fecha 13 de junio de 2017, la cual tiene como objetivo "promover el desarrollo integral en lo económico, social, cultural, y la participación efectiva en el ejercicio de los derechos civiles y políticos de la comunidad indígena del municipio de Santo Domingo de Guzmán, lo que incluye la protección y preservación de su propia cultura, de su tierra y territorio, $y$ especialmente de los recursos naturales renovables y no renovables, que constituyen el entorno ecológico de dicha comunidad" (Diario Oficial, 2016).

6. La emitida por el Concejo Municipal de Cacaopera, jurisdicción del Departamento de Morazán, quien acordó la Ordenanza Municipal denominada "Ordenanza sobre derechos de la comunidad indígena de Cacaopera del departamento de Morazán", 
publicada en el Diario Oficial Tomo $\mathrm{N}^{\circ}$ 425, N 205 de fecha 31 de octubre de 2019, la cual tiene como objetivo "Promover el mejoramiento de condiciones de vida $y$ el ejercicio pleno de los derechos civiles y políticos de la comunidad Kakawira del municipio de Cacaopera, lo que incluye la protección y revitalización de su propia identidad, organización tradicional ancestral, cosmovisión, espiritualidad, de su tierra, territorio y de los recursos naturales renovables y no renovables de su entorno ecológico” (Diario Oficial, 2019).

7. La emitida por el Concejo Municipal de Yucuaiquin, jurisdicción del Departamento de La Unión, quien acordó una Ordenanza Municipal de tutela de pueblos indígenas y que a la fecha de publicación de esta investigación aún se encuentra en proceso de publicación en el Diario Oficial.

\subsection{Políticas en materia indígena.}

Entre las políticas emitidas por el Estado salvadoreño se encuentran:

El Plan de Acción Nacional de Pueblos Indígenas, PLANPIES, formulado por el Gobierno de El Salvador, el equipo nacional de conducción indígena (ENACI) y El Fondo Internacional de Desarrollo Agrícola (FIDA) (FAO, 2019). E1 día veintidós de septiembre del dos mil catorce, el Gobierno salvadoreño adoptó el documento final de la reunión plenaria de alto nivel de la Asamblea General conocida como la Conferencia Mundial sobre los Pueblos Indígenas, con el objetivo de alcanzar los fines de la Declaración de las Naciones Unidas sobre los Pueblos Indígenas, actuando proactivamente con aportes importantes en la definición de su contenido (Ministerio de Cultura et al., 2017, p. 8).

En cumplimiento a lo anterior, el Gobierno de El Salvador participó e impulsó un proceso de consulta, liderado por los pueblos indígenas, para la elaboración del Plan de Acción Nacional de los Pueblos Indígenas -PLANPIES-, siendo E1 Salvador uno de los seis países a nivel mundial en elaborar e implementar un Plan de Acción de Pueblos Indígenas que buscó alcanzar los fines de la Declaración de las Naciones Unidas sobre los Pueblos Indígenas, el cual fue reconocido en la Asamblea General de la ONU en septiembre de 2017 como un ejemplo de Buenas Prácticas de trabajo entre Pueblos Indígenas y Gobierno, con el acompañamiento de Naciones Unidas, en el marco del décimo aniversario de la Declaración de las Naciones Unidas sobre Derechos de Pueblos Indígenas (ver tabla 3). E1 PLANPIES dentro de sus Acciones Estratégicas, da pauta a realizar actividades y acciones encaminadas a fortalecer los Derechos de los Pueblos Indígenas, específicamente de la niñez y adolescencia indígena (Ministerio de Cultura, ENACI, FAO, FIDA, y PNUD, 2017).

La Política Nacional de Salud de Pueblos Indígenas, formulada por el Ministerio de Salud, en junio de dos mil dieciocho, publicada en el Diario Oficial, Tomo 419, No 110, el 15 de junio de2018 (Diario Oficial,2018).La política referida posee como finalidad "Garantizar el derecho a la salud integral de los Pueblos Indígenas de El Salvador, con enfoque intercultural y de género, reconociendo, respetando y armonizando los conocimientos y saberes indígenas en el Sistema Nacional de Salud (MINSAL, 2018, p. 31). 


\section{Tabla 3}

Acciones estratégicas del PLANPIES

\begin{tabular}{l|l}
\hline Área Estratégica & Acción Estratégica \\
\hline \multirow{2}{*}{$\begin{array}{l}\text { Impulsar el análisis de las leyes y políticas referidas a la niñez, juventud, mujeres, } \\
\text { personas adultas, personas adultas mayores y personas con discapacidad y población }\end{array}$} \\
LGBTI para determinar si están armonizadas con los estándares del derecho \\
indígenas, de no estarlo, procurar su adecuación.
\end{tabular}

Área Política/Jurídica

Quinquenal y todos aquellos instrumentos, políticas, planes y programas, por medio de la Mesa de Seguimiento del PLANPIES.

Impulsar el ajuste de la metodología del Censo de Población, tomando en cuenta el principio de auto identificación y el desarrollo de una campaña de sensibilización previa al censo

Procurar la participación Plena y Efectiva de los Pueblos Indígenas, incluyendo la juventud y las mujeres, en los espacios de decisión para la elaboración e implementación de políticas, programas, proyectos y servicios.

Procurar el desarrollo de mecanismos de participación plena y efectiva de los Pueblos Indígenas para la protección y conservación ambiental, acorde a la cosmovisión que minimice el impacto del Cambio Climático.

Área Estratégica Territorial /

Económica

\section{Área Estratégica Social}

Área de Identidad Cultural
Impulsar buenas prácticas de sistemas tradicionales Indígenas vinculadas a la adaptación y mitigación al Cambio Climático.

Promover censos en los municipios donde no los haya, con énfasis en la inseguridad alimentaria y nutricional, realizándose en los municipios con mayor presencia indígena.

Impulsar la ejecución de un programa de formación técnica en turismo comunitario, bajo la visión de identidad cultural de los Pueblos Indígenas

Diseñar e implementar programas sociales específicos y de atención diferenciada para la niñez, adolescencia, juventud, mujer, personas adultas mayores y personas con discapacidad Indígena para erradicar la discriminación.

Impulsar la creación de mecanismos al interior del Ministerio de Salud para garantizar el desarrollo de un Sistema de Salud Intercultural en Territorios Indígenas que aborde factores de riesgos sanitarios (salud sexual y reproductiva, alcohol, tabaco, malnutrición, y otros) con énfasis en niñez, mujeres, jóvenes y personas adultas mayores indígenas

Promover mecanismos al interior del Ministerio de Educación para garantizar el desarrollo de un sistema de educación intercultural que garantice la no discriminación de los Pueblos Indígenas en todas las instituciones educativas a nivel nacional.

Formular la creación de un programa de becas para la formación de jóvenes indígenas en los niveles de educación superior universitaria

Procurar la creación e implementación de mecanismos adecuados para impulsar intercambio de experiencias culturales entre niños, niñas, juventud, mujeres, mayores y ancianos de los Pueblos Indígenas nacional e internacionalmente

Impulsar el diseño e implementación de un programa para fortalecer capacidades técnicas de comunicadores y comunicadoras indígenas.

Fuente: Elaboración propia con base en el PLANPIES. 
Política de Agricultura Familiar Campesina, Indígena y Afrodescendiente de Centroamérica y República Dominicana, es un instrumento marco de políticas públicas específicas para la agricultura familiar de la Región SICA. La política sirve de marco de referencia a los diversos procesos de formulación de políticas y leyes en materia de agricultura familiar que se desarrollan en cada uno de los países de la región, en función del contexto socio económico, político e institucional nacional y regional, fue aprobada a través de la resolución CAC 02 2018 del Consejo de Ministros del Sistema de Integración Centroamericana (Resolución CAC 02 - 2018 del Consejo de Ministros del Sistema de Integración Centroamericana, 2018).

\subsection{El paradigma tutelar de la niñez $y$ adolescencia desde la concepción occidental.}

La niñez y la adultez desde la filosofía occidental, ha tenido tratamientos diferenciados desde tiempos remotos para la historia de la niñez, ese tratamiento diferenciado se orientó siempre a la superioridad de los adultos sobre la niñez a través del mandato y la autoridad, lo cual fue materializado en las instituciones jurídicas y políticas, sobre la vida y el desarrollo de la niñez.

Este tratamiento diferenciado, en lo familiar, se caracterizó de forma fundamental por los modos y pautas de crianza, considerando la subordinación peculiar de la niñez a la adultez, incluso hasta en la decisión de dar continuidad a su vida por razones sociales, familiares o de otra índole, mientras que, en lo jurídico, este tratamiento se caracteriza especialmente por las instituciones que justifican desde la ley, la constitución de la propia diferenciación social y familiar.

\subsection{Doctrina de la situación irregular}

Esta doctrina hace referencia a los niños y adolescentes que no reciben tratamiento, educación y los cuidados que corresponden a sus individualidades (CSJ, 2009). Establece la concepción de los niños como objetos de protección. La doctrina de la situación irregular no hace referencia a todo el núcleo poblacional; sino aquél segmento de niños abandonados, inadaptados e infractores; tampoco aborda todos los derechos; solamente los de protección y vigilancia, a partir de una definición negativa de estos actores sociales, que nace del desconocimiento o incapacidad de la niñez, y bajo esa visión, los vuelve objetos de protección, (CSJ, 2009). Con esta visión y ante la falta de políticas sociales adecuadas, el modelo tutelar crea entidades que dispongan de medidas consistentes en internar a estos sujetos, con fines supuestamente protectores (Weinberg, 2002).

El modelo tutelar, se encuentra enmarcado dentro de la escuela etiológica, la cual reproduce criterios criminológicos delsigloXIXyprincipios delsigloXX, entre ellos, la pobreza, marginalidad y delincuencia; lo cual permea las prácticas y las instituciones de este modelo; que por las condiciones personales de la niñez, se habilita al Estado a intervenir, para legitimar de esta forma, la institucionalización indefinida, que se considera un tratamiento adecuado a favor de la niñez (Beloff, 2008).

Su denominación de modelo tutelar, nace como una respuesta al tratamiento que se daba a los adolescentes en conflicto con la ley, quienes no eran tratados en los procesos penales, de forma distinta que los adultos, siendo la única diferencia la duración de las penas. En consonancia con lo anterior se creó 
una jurisdicción especializada en "menores", en la cual el Estado actúa en reemplazo de los padres, puesto que dichos menores no tienen capacidad legal plena para actuar, por lo que se requiere como elemento clave, una atención centrada en el bienestar, por medio de una intervención tutelar benevolente, por parte del Estado.

Las principales características de este modelo tutelar, pueden resumirse en cuatro (Coto Argueta y Vásquez Rivas, 2017, p. 28):

a. Los niños y adolescentes, son considerados como objetos de protección;

b. Se confunde en cuanto al tratamiento que se otorga víctimas y victimarios;

c. El juez opera como tutor; y

d. Las medidas de protección privilegian el acogimiento en instituciones de forma indefinida.

\subsection{Doctrina de la protección integral}

La doctrina de protección integral, según Simón (2008) se fundamenta en cuatro rasgos principales:

a. La visualización de la niñez y adolescencia como sujetos plenos de derechos y no como objeto de protección, reconociendo por lo tanto que todo niño, niña y adolescente es titular de todos los derechos y puede ejercerlos;

b. La integralidad, basada en el reconocimiento de todos los derechos para todos los niños, niñas y adolescentes; c. La diferenciación en el tratamiento de víctimas y victimarios; $y$

d. La diferenciación entre la protección jurídica y la protección social.

Esta doctrina de protección integral, debe estar basada, además, en una nueva concepción de la niñez y adolescencia, con un paradigma de ciudadanía, que no se limita a un cambio nominal de menor a niño, sino que exige un estado jurídico de plena participación y titularidad de todos los derechos fundamentales.

\subsection{Reforma legal de protección integral de la niñez y adolescencia}

El Estado Salvadoreño ratificó la Convención de Derechos del Niño dos meses después de su adopción, suscribiéndola en enero y ratificándola en abril de 1990; la primera ley de tutela de la niñez en El Salvador fue la Ley del Instituto Salvadoreño de Protección al Menor, posteriormente denominado Instituto Salvadoreño para el desarrollo Integral de la Niñez y Adolescencia, "ISNA", posteriormente se aprobó y entró en vigencia la Legislación Familiar, a través del Código de Familia a partir del uno de octubre de 1994, en la que se desarrolló un apartado sobre los derechos de la niñez y los principios emanados de la Convención de Derechos del Niño (Bolaños, 2011).

Así mismo se crearon tribunales especializados de familia y de menores, a nivel nacional, que conocieron de las vulneraciones de los derechos de la niñez y los casos de adolescentes en conflicto con la ley, quitándole esa competencia al ISNA; y separando con ello, el trato de las 
víctimas y de los victimarios, diferenciando así el tratamiento administrativo del judicial, e introduciendo en la normativa procesal, garantías para la niñez y adolescencia.

\subsection{La ley de protección integral de la niñez y adolescencia.}

La Ley de Protección Integral de la Niñez y Adolescencia, en adelante LEPINA, fue aprobada a través del Decreto Legislativo No. 839 el 26 de marzo de 2009, publicada en el Diario Oficial No 68, Tomo 383, de fecha 16 de abril de 2009; entró en vigencia parcial el 16 de abril de 2010 (Libro I sobre Derechos y Deberes de Niñas, Niños y Adolescentes), los Libros II sobre el Sistema Nacional de Protección y III sobre Administración de Justicia entraron en vigencia el 01 de enero de 2011. La Ley de Protección Integral de la Niñez y Adolescencia tiene como objetivo garantizar el ejercicio y disfrute pleno de los derechos y facilitar el cumplimiento de los deberes de toda niña, niño y adolescente en El Salvador y la creación del Sistema Nacional de Protección Integral de la Niñez y Adolescencia, fundado en la doctrina de protección integral.

\subsection{Las políticas de protección de la niñez y adolescencia}

En mayo de 1993 la Secretaria Nacional de la Familia y el Instituto de Protección al Menor, diseñaron la Primera Política de Atención a los Niños, la cual consistía en un conjunto de orientaciones y medios de protección de los derechos del niño o a la población menor de dieciocho años.

El Consejo Directivo del CONNA durante el periodo 2012-2013 elaboró la segunda política de protección de niñez y adolescencia a la luz de la doctrina de protección integral, la cual hasta la fecha de elaboración de la presente investigación, aun continua vigente; contó con una participación de 3,784 niñas, niños y adolescentes y de 3,557 personas adultas, entre ellas líderes yorganizaciones comunitarias, autoridades y funcionarios públicos, personal de entidades de atención, madres, padres, docentes, y representantes de iglesias (CONNA, 2013, p. 3).

\section{Objetivos}

\section{Objetivo general}

Identificar las condiciones materiales $y$ espirituales de la niñez y adolescencia de los pueblos Náhuat, Lenca y Kakawira, por medio de sus experiencias en términos de su temporalidad, ámbito espacial y contexto con la finalidad de formular un diagnostico situacional de la niñez y adolescencia indígena en E1 Salvador.

\section{Objetivos específicos}

Describir etnográficamente los Pueblos Náhuat, Lencas y Kakawira, así como sus antecedentes históricos, con la finalidad de analizar críticamente sus condiciones materiales y espirituales de vida, a partir de la represión, marginación e invisibilización sistemática $y$ continua de que fueron objeto y la vulneración de sus derechos fundamentales y humanos a la que han sido sometidos en el devenir histórico por los patrones de conducta de los obtentores del poder en los diversos regímenes de turno.

Identificar el marco normativo salvadoreño en relación a la tutela efectiva de los Pueblos Indígenas, 
con la finalidad de establecer la existencia de derecho sustantivo en el marco normativo y la materialización del mismo a través de la creación de instituciones, procesos, reconocimiento de derechos y la condición de sujeto de derecho.

Analizar el marco normativo de protección integral de la niñez y adolescencia y su correspondencia o divergencia con la cosmovisión, principios, valores y discursos de la niñez y adolescencia indígena salvadoreña, con la finalidad de establecer si los formuladores de la política incorporaron la cosmovisión, principios, valores y discursos de los Pueblos Indígenas.

Analizar las políticas públicas en materia de tutela de Pueblos Indígenas en general y las políticas de niñez y adolescencia en particular, con la finalidad de determinar si su filosofía, objetivos, estrategias, líneas de acción, corrientes que la sustentan y paradigmas son acordes al abordaje de los fenómenos y situaciones desde la óptica de la cosmovisión, principios, valores y discursos de los Pueblos Indígenas.

\section{Metodología}

La metodología aplicada en la investigación fue la cualitativa fenomenológica, la cual se enfocó en las experiencias individuales subjetivas de los participantes. Responden a la pregunta ¿Cuál es el significado, estructura y esencia de una experiencia vivida por una persona, grupo o comunidad respecto de un fenómeno? El centro de indagación de estos diseños reside en las experiencias del participante o participantes.

Siguiendo a Creswell, 1998; Alvarez-Gayou, 2003; y Mertens, 2005 (Citados por Hernández
Sampieri, Fernández Collado, y Baptista Lucio, 2010) la investigación cualitativa fenomenológica realizada se fundamentó en una serie de premisas. Se describieron y comprendieron los fenómenos desde el punto de vista de los Pueblos Indígenas Náhuat, Lenca y Kakawira, a partir de su cosmovisión principios y valores; se realizó un análisis de sus discursos y el significado de ello, como el de reconocerse a sí mismos como perteneciente al grupo cultural indígena y reclamarse como miembro de ese pueblo, lo que constituye la autodefinición, un ejercicio individual de determinación de su propia identidad cultural reconociéndose en aquella del grupo. Se contextualizaron las experiencias en términos de su temporalidad, ámbito espacial y contexto. Se realizaron entrevistas a informantes claves, y se organizaron grupos focales de jóvenes de los Pueblos Náhuat, Lenca y Kakawira, quienes brindaron información relevante y novedosa, que permitió la recolección de información significativa de su cotidianidad, valores, principios y cosmovisión.

A continuación, se desarrollan las fases metodológicas en el proceso de esta investigación.

\section{Fase I: preparación}

Elección de las técnicas a utilizar en la investigación:

a. Entrevistas semiestructuradas: Fueron utilizadas para la extracción de cierta información en particular a través de los agentes claves, población afectada o conocedores de un tema específico. El instrumento para su aplicación fue un cuestionario, el cual constó de interrogantes de tipo abiertas con la finalidad de poder 
obtener información más profunda, detallada y descriptiva, debido a la libertad de expresión que aporta el entrevistado.

b. Grupos focales: Fueron realizados con la finalidad de provocar confesiones o auto exposiciones entre los participantes, a fin de obtener de estos, información cualitativa sobre el tema de investigación. La técnica de grupo focal se caracteriza por trabajar con instrumentos de análisis que no buscan informar sobre la cantidad de fenómenos, sino más bien interpretarlos en profundidad y detalle, para dar cuenta de comportamientos sociales y prácticas cotidianas. Las características más relevantes de los grupos focales son las siguientes:

- Interacción entre un grupo de personas

- Los participantes conocieron los objetivos del estudio.

- Grupos no mayores a 10 personas

- Grupos homogéneos

- Un moderador conduce el grupo

c. Observación participativa: Se aplicó un proceso que facultó a los investigadores a aprender acerca de las actividades del núcleo poblacional en estudio, en el escenario natural a través de la observación y participando en sus actividades. Fue usada como una forma de incrementar la validez del estudio, como observaciones que contribuyeran a tener una mejor comprensión del contexto y el fenómeno en estudio.

d. Consultas/ Asambleas con líderes del CCNIS: Se realizaron con la finalidad de interactuar con el núcleo poblacional indígena sobre la situación histórica, política, jurídica y socioeconómica que los atañe.

e. Bitácora de investigación: Se aplicó con la finalidad de generar un registro de información documental.

\section{Fase II: Elaboración}

Se formularon los siguientes instrumentos: cuestionario de informantes claves, el cual constó de interrogantes de tipo abierto, con la finalidad de obtener información relevante, profunda, detallada y descriptiva, debido a la libertad de expresión que aporta el entrevistado; carta de consentimiento informado, con la finalidad que el informante clave conociera el objetivo, justificación y beneficios de la investigación y que la información y datos aportados en la misma pueden ser publicados o difundidos con fines científicos, siempre y cuando se respeten los términos de confidencialidad; y, por último, la bitácora de investigación con la finalidad de generar un registro de información documental. Dichos instrumentos permitieron recabar la información necesaria para la realización del diagnóstico situacional del niño y adolescente indígena salvadoreño.

\section{Fase III: Implementación}

a. Se realizaron seis entrevistas con abuelos $\mathrm{y}$ tatas (actores claves en la comunidad) de los pueblos náhuat/pipil, lenca, kakawira (referentes nacionales y regionales) quienes participaron voluntariamente en el estudio, el tiempo de las entrevistas aproximadamente fue de treinta minutos cada una de ellas.

b. Se realizaron seis entrevistas con adolescentes de los pueblos náhuat/pipil, lenca, kakawira, 
quienes participaron voluntariamente en el estudio, el tiempo de las entrevistas aproximadamente fue de treinta minutos cada una de ellas.

c. Se realizó un grupo focal con adolescentes indígenas de los pueblos náhuat/pipil, lenca, kakawira, en la sede del Consejo Coordinador Nacional Indígena Salvadoreño, ubicado en Colonia Flor Blanca, Calle E1 Progreso, Reparto Rosedal Pasaje las Rosas, número siete, San Salvador, se contó con la participación de catorce jóvenes indígenas, nueve de ellos pueblo indígena náhuat/Pipil, cuatro del Pueblo Indígena Lenca y uno del Pueblo Indígena Kakawira, el tiempo de la sesión fue de cinco horas.

d. Se realizaron dos observaciones participativas, la primera de ellas con el Pueblo Indígena Náhuat / Pipil, la cual fue realizada en el terreno contiguo a la iglesia La Asunción del municipio de Izalco, departamento de Sonsonate, en el lugar denominado centro ceremonial el Llanito. Se contó con la participación de catorce jóvenes del Pueblo Náhuat / Pipil, en donde se desarrolló una reunión de jóvenes con temáticas sobre participación y organización. Posteriormente se celebró una actividad ceremonial con la cual se clausuró la actividad. El tiempo de duración de la actividad fue de cuatro horas. Así mismo, se realizó una observación participativa en una reunión de jóvenes del Pueblo Indígena Kakawira en la sede del Ministerio de Gobernación de la ciudad de San Francisco Gotera ubicada en la segunda calle poniente y tercera avenida Sur, del Barrio El Centro, en el Centro de Gobierno, de la ciudad de
San Francisco Gotera, la cual contó con la participación de once jóvenes. Se discutieron temáticas de espiritualidad y participación, a efecto de contribuir a fortalecer la identidad y cosmovisión indígena. El tiempo de duración de la actividad fue de cuatro horas, las cuales fueron registradas a través de la bitácora de investigación.

\section{Fase IV: Procesamiento de análisis de datos}

Se realizaron entrevistas con informantes claves, y se organizaron grupos focales de jóvenes de los Pueblos Náhuat, Lenca y Kakawira, quienes brindaron información relevante y novedosa. Así mismo, se realizó una observación participativa con los jóvenes indígenas referidos, y esto se registró a través de una bitácora de investigación. Posteriormente se transcribió la información recolectada de las entrevistas y de la observación, la cual fue vaciada en un software especializado denominado NVIVO. Se desarrolló un proceso de microanálisis línea por línea del texto, seleccionándose ideas centrales del mismo, y colocándose los nombres a las categorías. Se procesaron y recolectaron los datos hasta llegar al punto de no existir más datos relevantes, constituyendo con ello la saturación teórica. En este punto, el conjunto de categorías identificadas a partir del discurso de los informantes claves, en conjunto, permitieron responder a las interrogantes y objetivos de la investigación.

\section{Fase V: Validación}

El diagnostico se sometió ante la perspectiva y critica de los informantes claves. Se recibieron una serie de comentarios y retroalimentación sobre el estudio, los cuales permitieron refinar algunos aspectos del marco de referencia y de los resultados obtenidos, con el fin de garantizar que 
la investigación capte la cosmovisión, principios y valores que se quieren transmitir. Los comentarios realizados por los informantes claves llevaron a realizar cambios en la terminología, sustentados en la cosmovisión, principios y valores de los Pueblos Indígenas. Esta devolución de resultados facilitó validar los resultados y garantizar aspectos éticos con respecto al uso de los datos derivados de la investigación.

\section{Muestra}

El muestreo cualitativo consistió en seleccionar actores claves del núcleo poblacional indígena Náhuat Pipil, Lenca y Kakawira, quienes participaron voluntariamente en el estudio (ver tabla 4 sobre el perfil de las personas entrevistadas). Los informantes claves seleccionados fueron representantes ante el Consejo Indígena de Centro América, representantes ante El Fondo para el Desarrollo de los Pueblos Indígenas de América Latina y El Caribe, coordinación nacional y miembros del Consejo Coordinador Nacional Indígena Salvadoreño "CCNIS", representantes de los Concejos de Ancianos, representantes de los pueblos Náhuat Pipil,
Lenca y Kakawira, y jóvenes de los pueblos Náhuat Pipil, Lenca y Kakawira. El acceso a los informantes claves fue posible mediante contactos o gatekeepers (Hernández Sampieri, Fernández Collado, y Baptista Lucio, 2010), quienes facilitaron el proceso y contacto con los actores claves.

\section{Resultados cualitativos}

En los resultados cualitativos se identifican once categorías del fenómeno estudiado, los cuales se detallan a continuación: Pueblos Indígenas, niños, jóvenes, salud, educación, cosmovisión, identidad, participación, Ley de Protección Integral de la Niñez y Adolescencia (LEPINA), interés superior del niño, y Política Nacional de Juventud. Ver figura 1.

\section{Pueblos Indígenas}

"Los Pueblos Indígenas de El Salvador, presentan un referente cultural dificil de visualizar a simple vista, pues los rasgos culturales que usualmente identifican a un indigena en otras latitudes, como la lengua materna, y el traje tradicional, ya no están presentes" (Entrevista a Lenca 01, 2020).

\section{Tabla 4}

Perfil de personas entrevistadas

\begin{tabular}{|c|c|c|c|c|c|}
\hline \multicolumn{6}{|c|}{ Perfil de entrevistados } \\
\hline \multirow{2}{*}{ Pueblo al que representa } & \multirow{2}{*}{ Mujeres } & \multirow{2}{*}{ Hombres } & \multicolumn{2}{|c|}{ Rango } & \multirow{2}{*}{ Tota } \\
\hline & & & Adultos & Jóvenes & \\
\hline Pueblo Náhuat & 3 & 6 & 2 & 7 & 9 \\
\hline Pueblo Lenca & 0 & 4 & 2 & 2 & 4 \\
\hline Pueblo Kakawira & 1 & 2 & 2 & 1 & 3 \\
\hline Total de entrevistados & 4 & 12 & 6 & 10 & 16 \\
\hline
\end{tabular}

Fuente: Elaboración propia a partir de los datos generados por medio de las entrevistas realizadas. 
Figura 1. Categorías del fenómeno investigado identificadas de los resultados cualitativos.

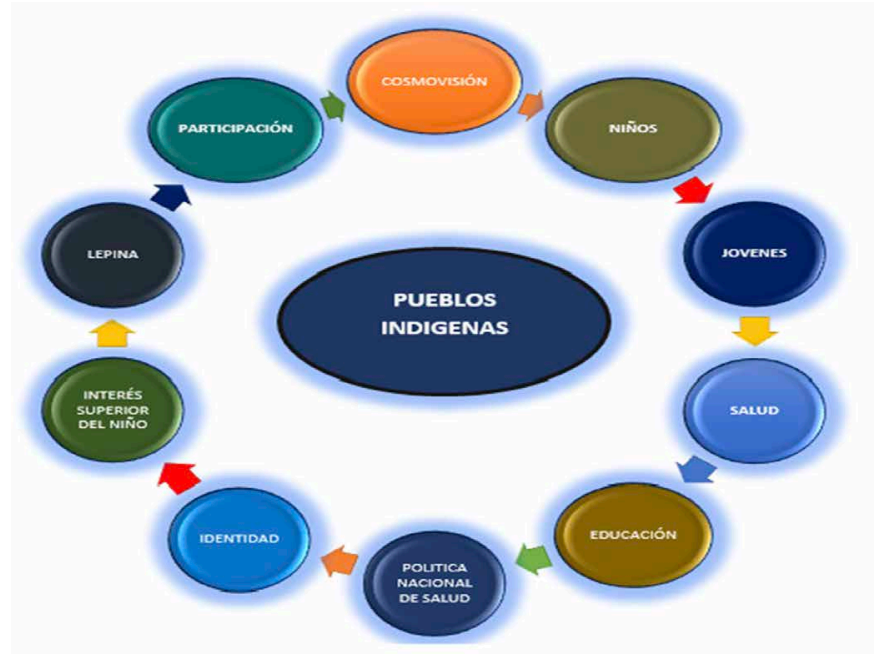

Fuente: Elaboración propia.

Los Pueblos Indígenas de El Salvador, han sufrido desde la invasión del imperio Español, un aniquilamiento sistemático y continuo de su población; lo cual no fue modificado con el surgimiento del Estado Salvadoreño, a través del proceso de independencia; conllevando a que los patrones de conducta de los obtentores de poder se mantuvieran inalterados; y condenando a los abuelos a venerar al Dios de los conquistadores, la abolición de su religión, saberes, la negación de sus instituciones, vestuario y lengua materna, la cual se perpetua hasta la actualidad.

"Se están perdiendo los valores, por el sistema que tenemos, el sistema occidental, esto causa la pérdida de valores propios de los Pueblos Indigenas". (Entrevista a Kakawira 01, 2020).

El proceso de alienación de la identidad del indígena salvadoreño, como resultado de la implementación sistemática y continua del sistema occidental, ha conllevado a la perdida $\mathrm{y}$ a veces al desconocimiento de los principios $\mathrm{y}$ valores indígenas; en razón que al no cimentarse y/o prohibirse el traspaso generacional de los mismos por los abuelos y tatas a las nuevas generaciones, se consolida el proceso de negación de su existencia dentro del Estado.

"Hay muchas cosas que se han ido perdiendo, lo que es enfocado en la cosmovisión en la manera de hacer las cosas, pero en el caso de como Pueblos Indígenas, siempre ellos nos enseñan lo esencial y lo básico, como decir, nosotros recordar porque estamos acá" (Entrevista a Nábuat, 01, 2020).

E1 aniquilamiento sistemático y continuo histórico por parte de los Gobiernos de turno, la negación de su existencia, la falta de una superestructura política, jurídica y económica 
estatal que proteja, garantice y satisfaga los derechos humanos como grupo vulnerable a este núcleo poblacional, ha generado las condiciones materiales actuales de pérdida de identidad y pertenencia de las nuevas generaciones que al no sentirse identificados niegan o esconden su arraigo por temor a ser rechazados; sin embargo, existe un reconocimiento de los Pueblos Indígenas de fortalecer la cosmovisión como piedra angular de su quehacer como sujetos.

"Estamos en el deber de rescatar nuestra cultura, de rescatar nuestros valores como Pueblos Indígenas" (Entrevista a Nábuat 02, 2020).

La cultura es un sistema de representaciones a través del cual se contextualizan y se da sentido a la existencia colectiva e individual, describe las realidades y la historia de sus integrantes y sus comunidades, por ello, más allá de ser el vehículo para transmitir de generación en generación los usos, costumbres y tradiciones indígenas, permite construir un diálogo, una compenetración entre seres diversos y diferentes, con recursos materiales y humanos que aportan conscientemente para la coexistencia digna de los grupos indígenas y no indígenas en cada contexto histórico y social de la colectividad.

\section{Niños y adolescentes}

"Para los Pueblos Indígenas si es importante garantizar el pleno derecho de la garantía fundamentales del niño y de la niña" (Entrevista a Nábuat 03, 2020).

Existe un reconocimiento pleno de las obligaciones del Estado de respetar, proteger y satisfacer los derechos del niño para los Pueblos Indígenas, en razón que la tutela efectiva de los mismos, se convierte en la piedra angular sobre la que se erige todo el andamiaje de garantías fundamentales de derecho.

"No hay distinción si son jóvenes, niños, o mujeres para poder platicar con ellos de la danza, pero en nuestras reuniones siempre estamos todos, todo es colectivo" (Entrevista a Lenca 02, 2020).

El sentido de colectividad en la cotidianidad indígena, elimina la fragmentación occidental de la sociedad en grupos (Persona mayores, adolescentes, mujeres y otros), lo que permite la interacción de todos los integrantes de la comunidad en las diversas actividades que realizan.

"Cada mes o cada fin de mes con los jóvenes y los niños vamos transmitiendo los conocimientos" (Entrevista a Nábuat, 04, 2020).

El resguardo de los saberes y la cosmovisión indígena a través de la interacción generacional y la educación de aprender haciendo en la cotidianidad, fortalece los procesos de intercambio de conocimientos y de educación en los procesos de formación que se realizan cada fin de mes; pues estos no se encuentran aislados como se aparenta, en razón que las enseñanzas programáticas se fortalecen y consolidan en la cotidianidad de los aprendizajes de los niños y adolescentes en los diversas actividades y roles que desempeñan dentro de la comunidad.

"Si nos damos cuenta, ya nuestros mayores van de salida, nosotros vamos a llegar también a ese punto, y si nosotros no preparamos desde la niñez, ellos no van a tener tampoco que hacer cuando estén en la juventud" (Entrevista a Nábuat 05, 2020). 
Se reconoce la necesidad imprescindible de transmitir los conocimientos ancestrales a las nuevas generaciones, con el fin de postergar el legado de los saberes de los abuelos, en razón que al resguardar los conocimientos ancestrales se perpetúa la cosmovisión, identidad, valores y principios del indígena.

"Intentan que todos los jóvenes nos reunamos un día y discutamos algunos temas especificos o que nos formemos más, pero de abi salen otros factores de que están unos que están estudiando o pues otros que se dedican a otras labores y estamos viendo que es difícil que nos podamos estar viendo mes a mes, cada quince días, o que se yo, entonces esos factores hay que tomarlos en cuenta porque no todos los jóvenes tienen los mismos caminos, los mismos pensamientos, y cada quien está como ocupado en algo" (Entrevista a Lenca 03, 2020).

Se evidencia desinterés por parte de los jóvenes indígenas del aprendizaje cosmogónico, influenciado por el proceso de alienación de mercado del sistema occidental en el cual viven inmersos los mismos; pues factores exógenos sustentados por la globalización y la interconectividad, facilitan la pérdida de identidad que favorece la anulación de la personalidad de grupo.

\section{Salud}

"Este sistema de salud y los sistemas ancestrales pueden caminar juntos". (Entrevista a Lenca 03, 2020).

Los Pueblos Indígenas en E1 Salvador reconocen al sistema de salud estatal, y coinciden en que ciertos padecimientos o enfermedades deben requerir los cuidados paliativos del sistema; sin embargo, exigen el reconocimiento del sistema de salud ancestral indígena paralelo y coexistente al estatal, razón por la cual una de las principales exigencias como derecho fundado en el principio de libre determinación de los pueblos es la garantía de respeto y protección por parte del Estado de la medicina ancestral.

Los conocimientos y saberes en salud también son importantes en las comunidades indígenas desde procesos prenatales, donde es importante la figura de la "Partera", así como otros agentes de salud comunitarios indígenas que participan en el ciclo de vida de las y los miembros de la comunidad. Dentro del proceso educativo comunitario, también es de suma relevancia el traspaso de conocimientos hacia las nuevas generaciones, las cuales guardan una relación directa con la madre tierra y las propiedades curativas y de sanación que poseen, siendo importante mencionar que en la visión de los pueblos indígenas existen enfermedades que afectan lo físico, provenientes de la desarmonía de "energías" de las personas o de un colectivo de personas, ya sean éstos internos o externos de las comunidades

"Hay más que todo médicos tradicionales, le decimos a la mujer quintaura es un médico tradicional en la mujer y el hombre un médico tradicional en las comunidades, se juegan dos cosas la medicina natural y la medicina química" (Entrevista a Lenca 02, 2020).

En la visión de los Pueblos Indígenas existen enfermedades que afectan lo físico provenientes de la desarmonía de energías" de las personas o de un colectivo de personas, ya sean éstos internos o externos de las comunidades, razón por lo que el reconocimiento de la medicina ancestral indígena es de vital importancia para los Pueblos Indígenas. 


\section{Educación}

"La educación es una empresa, que no se adecua a la propia realidad de nuestro pueblo y una educación que está influenciada por otras Repúblicas, se nota cuando el niño llega a la casa" (Entrevista a Lenca 04, 2020).

Históricamente en los programas curriculares no se incluye la cosmovisión, principios y valores indígenas, menoscabando con ello el aprendizaje significativo de los Pueblos Indígenas en materia escolar, en razón que únicamente son exaltadas las virtudes del mundo occidental, omitiendo la historia, cultura, saberes entre otros aspectos de los Pueblos Indígenas de El Salvador.

El proceso de enseñanza aprendizaje indígena se centra en la cosmovisión, valores y principios indígenas, bajo el principio pedagógico de aprender haciendo, fortaleciendo las identidades comunitarias, a través de la agricultura, artesanía, cosmovisión y la relación entre el ser humano y la naturaleza.

"Hay talleres también, tenemos la escuela que es Kalabuinita, en el idioma Kakawira significa escuela de la cultura de la cosmovisión y la espiritualidad de los Pueblos Indígenas" (Entrevista a Kakawira 02, 2020).

La protección de las lenguas maternas se encuentra positivisado en el artículo sesenta y dos, inciso segundo de nuestra Constitución de la República, elevándolo a la categoría de patrimonio cultural, lo cual obliga al Estado a preservarlo, difundirlo, respetarlo y protegerlo. En razón de ello, La Asamblea Legislativa aprobó el día uno de febrero de dos mil diecisiete el Decreto Legislativo número 528, con la finalidad de declarar el día veintiuno de febrero de cada año como el "Día Nacional de la Lengua Náhuat”, el cual fue publicado en el Diario Oficial, Tomo No. 414, No. 29 de fecha 10 de febrero de 2017.

Sin embargo, del conjunto de lenguas maternas dentro del territorio nacional, el Estado sólo protege la lengua náhuat, minimizando a otras de igual importancia, como el potón y el Kakawira, coartando el derecho a conservar, desarrollar y expresarse en su propia lengua, elemento vital para la supervivencia de las culturas indígenas, en razón que en la mayoría de casos, es a través de la oralidad donde se constituye la transmisión de los conocimientos ancestrales y su identidad; forjando con ello la integralidad de la herencia cultural que les han legado sus ancestros, al reconocerse a sí mismos como perteneciente al grupo cultural indígena y reclamarse como miembro de ese pueblo. La autodefinición implica un ejercicio individual de determinación de su propia identidad cultural reconociéndose en aquella del grupo.

"El hecho que estamos aqui es para nosotros de irnos empoderando, que nuestros ancestros, o nuestros tatas nos estén educando sobre sus culturas" (Entrevista a Nábuat 02, 2020).

Existe por parte de la juventud indígena organizada un férreo compromiso por aprehender y comprender la dimensionalidad de su cultura y salvaguardar con ello la identidad de su pueblo, con el propósito de reconocerse a sí mismo como perteneciente al núcleo poblacional indígena y reclamarse como miembro de ese pueblo, trasmitiéndolo posteriormente a las nuevas generaciones e implementándolo en su cotidianidad. 


\section{Cosmovisión}

"El intercambio de conocimientos en los lugares sagrados como muchos le dicen ahora las ruinas, para nosotros no son ruinas, son lugares sagrados, lugares donde se concentra la energía del conocimiento, la energía de la ciencia para poderse curarse uno, pero todo eso es en base que la persona tenga la convicción que si pertenece a nuestro pueblo y entonces la gente va bien enmarcada en su conocimiento, va bien enmarcada de que tienen esa fe, esa convicción que existe esa sanidad" (Entrevista a Nábuat 04, 2020).

El despojo violento de las tierras propiedad de los Pueblos Indígenas a las cuales fueron sometidos durante el devenir histórico a través de la creación de marcos normativos e instituciones, legalizaron y legitimaron la concentración de la tenencia de la tierra en una clase social dominante, propiciando las luchas históricas reivindicativas por la tenencia de la tierra y las condiciones de precariedad marginal de subsistencia en que se encontraban los Pueblos Indígenas, tierras en las que en muchas de ellas se encontraban lugares sagrados; razón por la cual los lugares sagrados no pueden ser considerados como ruinas.

Conjuntamente a ello, los procesos de aniquilamiento sistemático y continuo de los saberes por parte de los obtentores del poder, así como la negación de su identidad y cosmovisión, produjo el desmontaje de la capacidad del sujeto deforjar ideas, representaciones e interpretaciones que procesen y comprendan la realidad en que se concibe el universo, propiciando con ello el desmontaje de su cultura.

"Nosotros como jóvenes estamos trabajando en rescatar nuestros conocimientos, nuestra espiritualidad, nuestra cosmovisión" (Entrevista a Nábuat 05, 2020).
El entorno inmediato en que se desarrolla el indígena, está rodeado de los guías espirituales que conviven con ellos y de una u otra manera se comunican con los seres humanos mediante signos, símbolos, sonidos o señales que los animales u otros elementos que la Madre Naturaleza brinda, de ahí que al comprender la integralidad de un todo armónico exista un compromiso de los adolescentes indígenas por reivindicar y dignificar los procesos de representación e interpretación de la realidad.

\section{Identidad}

"La identidad, su identificación sobre la vestimenta, las medicinas, el dialogo de algunas enseñanzas, el Nábuat y el poder de saber es el tema de la identidad" (Entrevista a Nábuat 04, 2020).

"Hagamos valer nuestros conocimientos y saberes, esa es nuestra intención, esa es nuestra preocupación, para que algún día todos podamos comprender" (Entrevista a Nábuat 04, 2020).

Ser indígena supone sentirse parte integrante de la herencia cultural que les han legado sus ancestros, reconocerse a sí mismo como perteneciente al grupo cultural indígena $\mathrm{y}$ reclamarse como miembro de ese pueblo. La autodefinición implica un ejercicio individual de determinación de su propia identidad cultural reconociéndose en aquella del grupo.

\section{Participación}

A nivel nacional se ha instalado una red nacional de juventud indígena, con representación de jóvenes de las comunidades de los tres Pueblos Indígenas: Náhuat/pipil, Lenca y Kakawira, abordando iniciativas como el fortalecimiento de capacidades, cosmovisión según su Pueblo 
Indígena, desarrollo de comunicación indígena y acompañamiento logístico de eventos nacionales de importancia en la agenda de los diferentes procesos de los Pueblos Indígenas.

"La comunidad Lenca está estructurada en dos partes, nosotros mantenemos siempre todo lo indígena, contamos con un consejo de anciano mayor que 10 conforman 4 ancianos mayores y 4 ancianos menores; luego a los lados tenemos los chanes, y luego después de eso, contamos con una junta directiva jurídica para poder ver los trabajos sociales políticos y culturales de lo demás" (Entrevista a Lenca 02, 2020).

"El sistema comunitario Kakawira está organizado en base a un consejo que está conformado por trece de personas, está conformado por personas mayores, personas menores y personas mujeres; esos son los tres niveles que se mantienen y también el consejo está conformado por guias espirituales" (Entrevista a Kakawira 01, 2020).

"Nos encontramos en una dirección con que está formada con directivas, la directiva se compone de un presidente, vicepresidente, secretario $y$ un tesorero y vocal. Donde existe un consejo de ancianos, donde se ejerce la dirección de la espiritualidad, y luego contamos con una dirección de medicina natural, con eso contamos y también manejamos el tema de la medicina" (Entrevista a Nábuat 04, 2020).

\section{Ley de protección integral de la niñez y} adolescencia.

"Hemos estudiado a fondo algunos artículos de la ley; si la conocemos. La ley busca la protección integral de la niñez y la adolescencia, la ley protege integralmente a los niños y también su integridad tanto física como mental" (Entrevista a Nábuat 06, 2020).
Existe un conocimiento pleno e integral por parte de la mayoría de los integrantes de los Pueblos Indígenas sobre la Ley de Protección Integral de la niñez y adolescencia, razón por la cual es con base a la cosmovisión, de principios y valores indígenas los señalamientos a instituciones, principios, valores y filosofía que sustenta e integra el marco normativo referido.

\section{Interés superior del niño}

"Para los Pueblos Indígenas es importante también ver el cumplimiento de los deberes y no sólo los derechos, hay que hablarle de sus deberes y obligaciones que tiene primeramente con su papá y mamá, con el abuelo, la abuela, con la familia con el entorno; y cuando habló del entorno, estoy hablando sobre el cuido a la madre tierra, los recursos naturales y todo aquello que tiene ver cómo mantener las relaciones armoniosas a nivel de la familia y la comunidad" (Entrevista a Náhuat 03, 2020).

Los Pueblos Indígenas señalan como una de las principales debilidades de la ley el empoderamiento del niño y del adolescente de sus derechos, sin correspondencia a sus obligaciones como integrante de la comunidad, a través de la cual subyacen relaciones con los padres, abuelos y demás miembros de la familia, así como sobre el cuido a la madre tierra, los recursos naturales y todo aquello que tiene ver cómo mantener las relaciones armoniosas a nivel de la familia y de comunidad en su contexto material y espiritual.

"Se ha perdido autoridad tanto para los padres como para los maestros, pues se le ha dado mucha fuerza a esta ley (LEPINA), que ha venido a romper con todo el esquema familiar; la identidad cultural, la cosmovisión 
indigena; pues choca con los principios de los Pueblos Indigenas" (Entrevista a Lenca 01, 2020).

Los Pueblos Indígenas manifiestan que la ley les impide el derecho de corrección; en razón de no poder ejercer autoridad o imponer la disciplina correspondiente, vulnerando con ello los principios, valores y cosmovisión del proceso de enseñanza aprendizaje indígena.

Así mismo manifiestan que no es una disputa con la ley, sino que en razón de no haber sido consultados durante el proceso de formulación de la misma, ello ha conllevado a discrepancias culturales que afectan el proceso mismo de aprendizaje del niño y del adolescente.

\section{Política nacional de protección integral de} la niñez y de la adolescencia de E1 Salvador 2013 - 2023

"No fuimos consultados" (Entrevista a Nábuat 06, 2020).

La consulta de consentimiento libre, previo e informado es un derecho humano colectivo de los Pueblos Indígenas que les ayuda a prevenir que puedan ser vulnerados sus derechos y se sustenta en principios internacionales como la libre determinación, la igualdad, la identidad cultural, el pluralismo, el respeto a la tierra, territorio, recursos naturales, entre otros. El menoscabo de este derecho vulnera la autonomía, autogobierno, la cultura propia, y el derecho de definir sus prioridades en el proceso de desarrollo de los Pueblos Indígenas.

Es un derecho que promueve el diálogo intercultural, al buscar que se garantice la participación de los grupos indígenas en la toma de decisiones de proyectos que los puedan afectar, con el fin de proteger sus derechos fundamentales y humanos como sujetos de derecho.

"Es de vital importancia la consulta, porque es la manera en que nosotros nos comunicamos y es la manera en que nosotros decidimos a través de nuestros consejos comunitarios o decidimos que es lo que se puede hacer a través de nuestro círculo de la palabra, tomando en cuenta la decisión de toda la comunidad; entonces ¿cómo estar a favor de una ley que nos ha tomado en cuenta?" (Entrevista a Nábuat 06, 2020).

Los Pueblos Indígenas señalan que no existió durante el proceso de formulación de la política referida el derecho a una consulta de consentimiento libre, previo e informado, lo que conlleva a la negación de la existencia del núcleo poblacional; así como a la marginación de sus instituciones, procesos, y conocimientos ancestrales; vulnerando con ello derechos fundamentales y humanos de los Pueblos Indígenas estratificado en el segmento niñez y adolescencia.

El derecho de participación de los Pueblos Indígenas en situaciones que impliquen una afectación a ellos y a sus derechos es un método de reconocimiento de los pueblos como autónomos y con libre determinación para darles la posibilidad de definir sus prioridades para desarrollarse.

La consulta de consentimiento libre, previo e informado es un derecho y un instrumento para la participación en las decisiones sobre todos los asuntos que les conciernen a los Pueblos Indígenas. Al aplicar la consulta de consentimiento libre, previo e informado se 
reconoce el derecho de los Pueblos Indígenas a la autonomía, autogobierno, la cultura propia, y el derecho de definir sus prioridades en el proceso de desarrollo con base al Convenio 169 artículos 2.b, 5, 7.1, Declaración de las Naciones Unidas sobre los derechos de los Pueblos Indígenas artículo 4, Art 32 de la Ley de Cultura y al párrafo 19 literal "c", de las observaciones finales sobre los informes periódicos 18 y 19 de E1 Salvador 2019 del Comité para la Eliminación de la Discriminación Racial. Sin embargo, Balmore Zanco, uno de los nahuat entrevistados, sostiene que "La consulta contribuye a la protección de los derechos de los Pueblos Indígenas cuando entran en riesgo frente a las demandas y los requerimientos de sociedades numéricamente mayoritarias, y con mayor poder de decisión en las esferas de lo público y lo privado”.

\section{Conclusiones}

La investigación identificó la procedencia, población e identidad de los Pueblos Náhuat, Lencas y Kakawira así como su autodefinición de ser indígena en El Salvador, el cual se caracteriza por su conciencia de pertenecer o descender de un Pueblo Indígena, sus prácticas espirituales, su tejido organizativo, su auto determinación de ser indígena, la conservación de sus conocimientos y saberes, rasgos físicos, su especial relación con la madre tierra y los recursos naturales y en algunas ocasiones por su lengua y su vestuario.

Los resultados expuestos en la presente investigación determinaron que los Pueblos Náhuat, Lencas y Kakawira han sufrido en el devenir histórico un aniquilamiento sistemático y continuo de su población; en el que los patrones de conducta de los obtentores del poder se mantuvieron inalterados. Se ha condenado a los Pueblos Indígenas a la abolición de su cultura, cosmovisión, religión, negación de sus instituciones, sistema de salud, sistema económico, forma de organización, vestuario y lengua materna, la cual se perpetúa hasta la actualidad.

Es importante establecer que con base en los resultados hablar de niñez y adolescencia indígena en El Salvador, es hablar de procesos de represión e invisibilización; si la niñez y adolescencia se enmarca como población vulnerable se profundiza y agrava más en el núcleo poblacional indígena; en razón que los índices de pobreza extrema y marginalidad en el que se encuentran inmersos, vuelve más acuciante el acceso a la educación, salud, agua de consumo humano, vivienda, desarrollo humano, sostenibilidad del medio ambiente, entre otros y se agudiza al carecer de información detallada y datos desagregados en el desarrollo de los esfuerzos censales y de encuestas recientes que permitan establecer criterios para la formulación e implementación de políticas y programas gubernamentales y municipales; así como de un marco normativo acorde a las necesidades materiales de la niñez y adolescencia indígena.

Con base en la investigación se estableció que los Pueblos Náhuat, Lencas y Kakawira sufrieron vulneración de sus derechos fundamentales $y$ humanos, así como procesos de invisibilización y negación de forma sistemática y continua a lo largo de la historia, por medio del surgimiento de una superestructura política y jurídica que legalizó y legitimó la represión estatal y que como una de las diversas consecuencia, provocó la desarticulación de la organización social, conllevó a la negación legal y de hecho, del derecho a 
organizarse a lo largo del devenir histórico de nuestro país. Sin embargo, posterior a los acuerdos de paz se materializaron condiciones que emanciparon sustantiva y materialmente su derecho de asociación y organización, fundado en sede constitucional a partir del artículo 7, lo que provocó la posibilidad de la creación de asociaciones, como el establecimiento de las condiciones de libre desenvolvimiento de éstas.

Los resultados permitieron identificar un reconocimiento del sistema de salud estatal y de su importancia como instancia de cobertura nacional de prestación de servicios de salud por parte de los Pueblos Indígenas. Sin embargo, exigen el reconocimiento del sistema de salud ancestral paralelo y coexistente al estatal, razón por la cual una de las principales exigencias como derecho fundado en el principio de libre determinación de los pueblos es la garantía de respeto y protección por parte del Estado de la medicina ancestral indígena.

Los resultados determinaron que históricamente el proceso de enseñanza aprendizaje indígena, de enseñar haciendo no se encuentra incorporado en el currículo nacional, generando con ello desvinculación con su cosmovisión, en razón de la carencia de un aprendizaje significativo de los Pueblos Indígenas en materia escolar; pues el currículo nacional exalta las virtudes del mundo occidental, omitiendo y negando la historia, cultura, saberes, personajes entre otros aspectos de los Pueblos Indígenas de El Salvador.

Los resultados señalan que para los Pueblos Indígenas es neurálgico el resguardo de los saberes y la cosmovisión indígena a través de la interacción generacional y la educación de aprender haciendo en la cotidianidad, en razón que fortalece los procesos de intercambio de conocimientos y de educación en los procesos de formación; pues las enseñanzas programáticas se fortalecen y consolidan en la cotidianidad de los aprendizajes de los niños y adolescentes en las diversas actividades y roles que desempeñan dentro de la comunidad.

Los Tatas reconocen la necesidad imprescindible de transmitir los conocimientos ancestrales a las nuevas generaciones con el fin de postergar su legado, al resguardar los conocimientos ancestrales se perpetúa la cosmovisión, identidad, valores y principios del indígena. Sin embargo se evidencia desinterés por parte de los jóvenes indígenas de la cosmovisión, influenciado por el proceso de alienación de mercado del sistema occidental en el cual viven inmersos los mismos, pues factores exógenos sustentados por la globalización y la interconectividad, facilitan la pérdida de identidad que favorece la anulación de la personalidad de grupo.

Los resultados indican que existe un proceso acentuado de transculturización y alienación de la cultura occidental en la juventud indígena salvadoreña, que ha generado la pérdida de valores y principios ancestrales, sin embargo, existe conciencia y compromiso de fortalecimiento de la identidad, valores y principios a través del intercambio de conocimientos en los lugares sagrados ancestrales, así como de la organización de la juventud indígena a nivel nacional.

La investigación determinó que las lenguas maternas de los Pueblos Indígenas gozan de protección en sede constitucional, sin embargo, el legislador las desvaloriza y vulgariza al 
establecerles un carácter de autóctonas; así mismo a pesar de encontrarse positivisada durante más de treinta y cinco años, su protección y respeto fue incipiente o nulo por parte de los Gobiernos de turno, si bien, se han logrado algunos avances en cuanto a protección, sólo han sido en atención de salvaguardar la lengua náhuat, no así el potón, el kakawira y otras lenguas maternas, que sin ser oficial el dato tendrían el carácter de lenguas muertas.

En atención de conservar, desarrollar y expresarse en su propia lengua, la oralidad se constituye como piedra angular para la transmisión de los conocimientos ancestrales y su identidad; forjando con ello la integralidad de la herencia cultural que les han legado sus ancestros, al reconocerse a sí mismos como perteneciente al grupo cultural indígena y reclamarse como miembro de ese pueblo. La autodefinición implica un ejercicio individual de determinación de su propia identidad cultural reconociéndose en aquella del grupo.

En sede constitucional históricamente se negó de forma sistemática y continua la condición de sujeto de derecho de los Pueblos Indígenas en El Salvador, siendo reconocido sustantivamente a partir de la reforma al artículo sesenta y tres de la Constitución, el día nueve de mayo de dos mil doce, y su posterior ratificación el día catorce de junio del dos mil catorce. Sin embargo la materialización del articulado es una deuda pendiente para los Pueblos Indígenas en El Salvador hasta la fecha de publicación de esta investigación.

En materia de legislación secundaria, las regulaciones que afectan a los Pueblos Indígenas históricamente fueron lesivas y vulneradoras de sus derechos. En razón que desarraigaron a la población de sus tierras, a través de las instituciones de la expropiación y extinción de ejidos, desarticularon la organización social indígena, destruyeron y desconocieron sus instituciones y prohibieron su cosmovisión, lengua y vestuario, por lo que nuestro marco normativo secundario carece de un desarrollo sustantivo en materia de derecho indígena.

La formulación de las ordenanzas municipales de Nahuizalco, Izalco, Panchimalco, Cuisnáhuat, Santo Domingo de Guzmán, Cacaopera y Yucuaiquín en materia de tutela a los Pueblos Indígenas, prescindió de la participación de referentes de los Pueblos Indígenas según los entrevistados, vulnerando con ello el derecho a la consulta de consentimiento libre, previo e informado con base al Convenio 169 artículos 2.b, 5,7.1.,la Declaración de las Naciones Unidas sobre los derechos de los Pueblos Indígenas artículo 4, la Declaración Americana sobre los derechos de los Pueblos Indígenas Artículos XVIII. numeral 4, XX. numeral 4, Art 32 de la Ley de Cultura y al párrafo 19 literal "c", de las observaciones finales sobre los informes periódicos 18 y 19 de El Salvador 2019 del Comité para la Eliminación de la Discriminación Racial.

El ámbito espacial de validez de las ordenanzas municipales referidas, se circunscriben únicamente a la jurisdicción del municipio y a su vez quedan supeditadas a las agendas político partidarias que los Gobiernos locales de turno realizan durante su gestión; aunado lo anterior a la desarmonización con los estándares internacionales del Derecho de Pueblos Indígenas que la sociedad internacional ha provisto para la efectiva protección, respeto y garantía de sus derechos. 
Los resultados establecieron que los dirigentes del movimiento indígena salvadoreño y la mayoría del núcleo poblacional indígena consultado poseen conocimientos generales de La Ley de Protección Integral de la Niñez y Adolescencia, sin embargo manifiestan que no fueron consultados en el proceso de formulación de la misma, lo que vulnera su derecho de consulta de consentimiento libre, previo e informado con base al Convenio 169 artículos 2.b, 5, 7.1., la Declaración de las Naciones Unidas sobre los derechos de los Pueblos Indígenas artículo 4, la Declaración Americana sobre los derechos de los Pueblos Indígenas Artículos XVIII. numeral 4, XX. numeral 4, Art 32 de la Ley de Cultura y al párrafo 19 literal "c", de las observaciones finales sobre los informes periódicos 18 y 19 de El Salvador 2019 del Comité para la Eliminación de la Discriminación Racial.

En el proceso de formación de ley en materia de niñez y adolescencia, no se consideró la cosmovisión, valores y principios indígenas; en razón que se empoderó al niño y al adolescente de sus derechos, sin correspondencia a sus obligaciones como integrante de la comunidad, rompiendo con el esquema de familia indígena en razón que el niño al no poder ser reprendido y corregido en su conducta, no puede aprender haciendo, lo cual empodera derechos por encima de deberes, y rompe con la armonía de la comunidad.

Los Pueblos Indígenas reconocen los derechos fundamentales de los niños y adolescentes como piedra angular sobre la que se erige todo el andamiaje de garantías fundamentales de derecho, sin embargo, critican la falta de sentido de colectividad en la cotidianidad occidental, en razón que promueve la fragmentación de la sociedad en grupos (Persona mayores, adolescentes, mujeres y otros).

Los Pueblos Indígenas manifiestan que no fueron consultados sobre la Política Nacional de protección integral de la Niñez y de la Adolescencia de El Salvador 2013 - 2023, vulnerando el derecho universal de consulta de consentimiento libre, previo e informado, con base al Convenio 169 artículos 2.b, 5, 7.1., la Declaración de las Naciones Unidas sobre los derechos de los Pueblos Indígenas artículo 4, la Declaración Americana sobre los derechos de los Pueblos Indígenas Artículos XVIII. numeral 4, XX. numeral 4, Art 32 de la Ley de Cultura y al párrafo 19 literal "c", de las observaciones finales sobre los informes periódicos 18 y 19 de El Salvador 2019 del Comité para la Eliminación de la Discriminación Racial. El referido derecho implica el menoscabo a la autonomía, autodeterminación, autogobierno, cultura, y el derecho de definir sus prioridades en el proceso de desarrollo, razón por la que se violaron derechos fundamentales y humanos de la niñez y adolescencia indígena salvadoreña.

La vulneración del derecho de consulta de consentimiento libre, previo e informado, abre la posibilidad por quien se considere agraviado de denunciar ante el sistema nacional de protección de derechos humanos, la derogación de la Política Nacional de protección integral de la Niñez y de la Adolescencia de El Salvador 2013 - 2023, con el fin de salvaguardar los derechos de la niñez y adolescencia indígena salvadoreña, menoscabados desde la entrada en vigencia de la misma. 
En caso de omisión del Estado salvadoreño, se abre la posibilidad por quien se considere agraviado de acudir al Sistema de Protección Regional de Derechos Humanos para que sancione y repare en las dimensiones que considere pertinente, la vulneración del derecho de consulta de consentimiento libre, previo e informado.

En futuras investigaciones académicas los hallazgos encontrados por el diagnostico situacional de niñez y adolescencia indígena pueden utilizarse de insumos de partida para el abordaje en la materia.

\section{Recomendaciones}

Debe realizarse un estudio minucioso, exhaustivo e integral de la Ley de Protección Integral de la Niñez y Adolescencia, incorporando en las discusiones a integrantes representativos del núcleo poblacional indígena. Con el propósito de incluir su cosmovisión, valores y principios indígenas; respetando su derecho de consulta de consentimiento libre, previo e informado, en el proceso de formulación de la misma para la salvaguarda de sus derechos fundamentales $y$ humanos con base al Convenio 169 artículos 2.b, 5 , 7.1., la Declaración de las Naciones Unidas sobre los derechos de los Pueblos Indígenas artículo 4, la Declaración Americana sobre los derechos de los Pueblos Indígenas Artículos XVIII. numeral 4, XX. numeral 4, Art 32 de la Ley de Cultura y al párrafo 19 literal "c", de las observaciones finales sobre los informes periódicos 18 y 19 de El Salvador 2019 del Comité para la Eliminación de la Discriminación Racial.

Debe derogarse la Política Nacional de protección integral de la Niñez y de la Adolescencia de El Salvador 2013 - 2023, y formularse una nueva que garantice la participación de representantes indígenas en su formulación. Con el fin de salvaguardar los derechos de la niñez y adolescencia indígena salvadoreña, menoscabados desde la entrada en vigencia de la política actual; en razón de la vulneración del derecho de consulta de consentimiento libre, previo e informado, en el proceso de formulación de la política.

Debe firmarse y ratificarse por parte del Estado Salvadoreño el Convenio 169 de la Organización Internacional del Trabajo y la Declaración de las Naciones Unidas sobre los derechos de los Pueblos Indígenas. Con la finalidad de establecer un efecto vinculante para salvaguardar los derechos de los Pueblos Indígenas dentro del territorio del Estado Salvadoreño; así como las responsabilidades del Gobiernos de respetar, proteger y satisfacer estos derechos.

Deben armonizarse las ordenanzas municipales vigentes dentro del Estado salvadoreño con los estándares internacionales del Derecho de Pueblos Indígenas entre las que se encuentran hasta la fecha de publicación de la presente investigación: 1). Sobre derechos de las comunidades indígenas asentadas en el Municipio de Nahuizalco, 2). Sobre derechos de la comunidad indígena de Izalco, 3). Ordenanza Municipal sobre derechos de la comunidad indígena de Panchimalco, 4). Sobre derechos de la comunidad indígena de Cuisnahuat, 5) Ordenanza municipal sobre derechos de la comunidad indígena de Santo Domingo de Guzmán, 6) Ordenanza sobre derechos de la comunidad indígena de Cacaopera del departamento de Morazán, las cuales manifiestan 
los entrevistados no fueron consultados, menoscabando su derecho de consulta de consentimiento libre, previo e informado de las ordenanzas municipales referidas.

Debe armonizarse el derecho a la consulta contemplada en las Ordenanzas Municipales con la normativa nacional y en conformidad con el Convenio 169 de la OIT, la Convención Internacional sobre la Eliminación de todas las Formas de Discriminación Racial, la Declaración de las Naciones Unidas sobre los derechos de los Pueblos Indígenas, la Declaración Americana sobre los derechos de los Pueblos Indígenas y los estándares internacionales.

Debe implementarse durante el proceso de formulación, reforma o derogación de las leyes, políticas, programas o cualquier otra reglamentación técnica jurídica del Estado, el derecho a la consulta de consentimiento libre, previo e informado de los Pueblos Indígenas, con el propósito de participación en las decisiones sobre todos los asuntos que les conciernen, pues al aplicar la consulta previa, libre e informada se reconoce el derecho de los indígenas a la autonomía, autogobierno, la cultura propia, y el derecho de definir sus prioridades en el proceso de desarrollo.

Creación de un Consejo Intergubernamental de Pueblos Indígenas, con el propósito de asesorar a los tomadores de decisión en el Gobierno, durante el proceso de formulación, reforma o derogación de las leyes, políticas, programas o cualquier otra reglamentación técnica jurídica del Estado que de forma directa o indirecta afecta el núcleo poblacional referido; así como en su aplicación y en la toma de decisiones sobre todos los asuntos que les conciernen, con la finalidad de subsanar las observaciones finales realizadas en los informes periódicos 18 y 19 de El Salvador 2019 del Comité para la Eliminación de la Discriminación Racial.

Deben realizarse consultas sobre la formulación de un protocolo u otro marco institucional nacional para garantizar el derecho de consentimiento libre, previo e informado, con la finalidad de subsanar las observaciones finales realizadas en los informes periódicos 18 y 19 de El Salvador 2019 del Comité para la Eliminación de la Discriminación Racial y cumplir con lo mandatado en el Convenio 169 artículos 2.b, 5, 7.1., la Declaración de las Naciones Unidas sobre los derechos de los Pueblos Indígenas artículo 4, la Declaración Americana sobre los derechos de los Pueblos Indígenas Artículos XVIII. numeral 4, XX. numeral 4, Art 32 de la Ley de Cultura y al párrafo 19 literal "c", de las observaciones finales sobre los informes periódicos 18 y 19 de El Salvador 2019 del Comité para la Eliminación de la Discriminación Racial.

\section{Referencias}

Alvarenga, P. (2006). Cultura y Ética de la Violencia. El Salvador 1880-1932 (Segunda Ed). San Salvador, El Salvador: Dirección de Publicaciones e Impresos, Consejo Nacional para la Cultura y el Arte, CONCULTURA.

Anderson, T. (2001). El Salvador 1932. San Salvador, El Salvador: Dirección de Publicaciones e Impresos.

Beloff, M. (2008). Los Derechos del Niño en el Sistema Interamericano. Buenos Aires, Argentina: Editores del Puerto. 
Bolaños, F. (2011). El Desarrollo Integral de la Niñez y Adolescencia Indigente en Razón de la Aplicación de los Principios Rectores por parte de las Instituciones Competentes Establecidas en la Ley de Protección Integral de la Niñez y Adolescencia. Universidad de El Salvador, San Salvador.

CNDH. (2016). La consulta previa, libre, informada, de buena fe y culturalmente adecuada: Pueblos Indigenas, Derechos Humanos y el papel de las Empresas. Ciudad de México: CNDH.

Comisión Internacional de Juristas. (2013). Libro Acceso a la justicia Recursos contra las violaciones de los derechos sociales en El Salvador. San Salvador.

CONCULTURA. (2000). Perfil de los Pueblos Indigenas de El Salvador.

CONNA.(2013). Política nacional de protección integral de la niñez y de la adolescencia de El Salvador 2013 - 2023. San Salvador.

Coto Argueta, L. A., y Vásquez Rivas, J. N. (2017). El Derecho de participación de la niñez y adolescencia en los procesos judiciales y administrativos de la Ley de Protección integral de la niñez y adolescencia. San Salvador.

CSJ. (2009). El Interés Superior del Niño Comentarios al Código de la Niñez y la Adolescencia. (M. Villamayor Huerta, Ed.). Asunción, Paraguay.

Dalton, R. (2006). El Salvador Monografía. San Salvador, E1 Salvador: UCA Editores.

Diario Oficial. Tomo $\mathrm{N}^{\circ} 392, \mathrm{~N}^{\circ} 126$, de fecha 6 de julio (2011). El Salvador.
Diario Oficial. Tomo $N^{\circ} 395, N^{\circ} 75$, de fecha 25 de abril (2012). El Salvador.

Diario Oficial. Tomo No 395, No 84, de fecha 9 de mayo (2012). El Salvador.

Diario Oficial. Tomo $\mathrm{N}^{\circ} 407, \mathrm{~N}^{\circ} 61$, de fecha 8 de abril (2015). El Salvador.

Diario Oficial. Tomo $\mathrm{N}^{\circ} 407, \mathrm{~N}^{\circ} 80$, de fecha 6 de mayo (2015). El Salvador.

Diario Oficial. Tomo 419, No 110, de fecha 15 de junio (2018). E1 Salvador.

Diario Oficial. (13 de junio de Junio de 2016). Ordenanza municipal sobre derechos de la comunidad indígena de Santo Domingo de Guzmán.

Diario Oficial. (31 de octubre de Octubre de 2019). Ordenanza sobre derechos de la comunidad indígena de Cacaopera del departamento de Morazán.

DIGESTYC. (2007). Boleta censal del VI Censo de Poblacion y V de Vivienda 2007. Ciudad Delgado.

DIGESTYC. (2008). VI de población y V de vivienda 2007. San Salvador: Ministerio de Economía.

Domínguez, J. A. (2007). Anastasio Aquino, Caudillo de las tribus Nonualcas. San Salvador, E1 Salvador: Ediciones Venado del Bosque.

FAO.(2018).Informe de Resultados preliminares del Censo de Población, vivienda e INSAN en Cacaopera. San Salvador. 
FAO. (2019). Contribuyendo a la gobernanza de la San sobre Pueblos Indígenas en el ciclo de Políticas Públicas. San Salvador: FAO.

Gould, J. L., y Lauria-Santiago, A. (2010). 1932 Rebelión en la oscuridad. San Salvador, E1 Salvador: Ediciones Museo de la Palabra y la Imagen.

Grinnel, R. M. (1997). Social Work Research and Evaluation: Quantitative and Qualitative Approaches (5 edición). Illinois: Peacock Publishers.

Hernández Sampieri, R., Fernández Collado, C., y Baptista Lucio, M. del P. (2010). Metodología de la investigación. (S. A. D. C. V. INTERAMERICANA EDITORES, Ed.) (Quinta edi). México D.F.: McGRAW-HILL.

Martínez, A. (2019). Entrevista personal. El Salvador.

Menjivar, R. (1980). Acumulación Originaria y Desarrollo del Capitalismo en El Salvador. San José, Costa Rica: Editorial EDUCA.

Ministerio de Cultura, ENACI, FAO, FIDA, y PNUD. (2017). Plan de Acción Nacional de Pueblos Indígenas (PLANPIES). San Salvador.

MINSAL. (2018). Política Nacional de Salud de Pueblos. San Salvador.

Rodríguez, G., Gil,J.,y García, E. (1996). Métodos de investigación cualitativa. Málaga: Aljibe.

Resolución CAC 02 - 2018 del Consejo de Ministros del Sistema de Integración Centroamericana, Resolución CAC 02 (27 de Julio de 2018).
Simón, F. (2008). Derechos de la Niñez y Adolescencia: De la Convención sobre los Derechos del Niño a las Legislaciones Integrales. Quito: Cevallos Editorial Jurídica.

Taylor, S.J.,y Bogdan, R. (1994). Introducción a los métodos cualitativos de investigación: La búsqueda de significados (2a edición). Barcelona: Paidós.

Weinberg, I. M. (2002). Convención Sobre los Derechos del Niño. Buenos Aires: Rubinzal Culzoni Editores. 